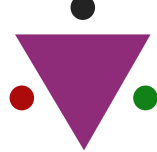 \\ Phytochemical Composition and Antioxidant Activity of Two Varieties of Unripe Date Palm
}

IJCRR

Section: Healthcare ISI Impact Factor (2019-20): 1.628

IC Value (2019): 90.81 $\operatorname{SJIF}(2020)=7.893$

(c) (7) (3)

Copyright@IJCRR

\section{Gayathri ${ }^{1}$, S. Thilagavathi²}

'PhD scholar, Department of Food Science and Nutrition, Periyar University, Salem; ${ }^{2}$ Assistant professor, Department of Food Science and Nutrition, Periyar University, Salem.

\section{ABSTRACT}

Introduction: Date palm (Phoenix dactylifera) has been used for nutritional and medicinal purposes. They are used as medicine for the treatment of several diseases and also highly recommended for pregnant women before and after delivery.

Objective: The present work aims to explore the phytochemicals present in unripened Dates (RD) and Yellow Dates (YD)and assess their antioxidant property.

Methods: Different solvents such as aqueous, methanol, benzene, petroleum ether and chloroform were used to extract the phytochemicals present in it DPPH (2, 2-diphenyl-1-picryl-hydrazyl-hydrate), FRAP (ferric reducing antioxidant power), Chelation of $\mathrm{Fe}^{2+}$ and SOD (superoxide dismutase) were used to assess the antioxidant activity.

Results: The screening of phytochemicals showed the presence of alkaloids, flavonoid, phenolic compounds, saponin, tannin, steroid and carbohydrate, however, the antioxidant activity revealed that the \% inhibition of DPPH, FRAP, Chelation of Fe ${ }^{2+}$ and SODwere about $94.05 \pm 2.73,77.91 \pm 2.96,88.02 \pm 2.50$ and $82.50 \pm 2.58$ respectively for $\mathrm{RD}$ and $85.13 \pm 2.74,68.03 \pm 2.66$, $79.64 \pm 4.0$ and $72.30 \pm 2.10$ respectively for YD.

Conclusion: Both YD and RD unripe date palm demonstrated high phytochemical content and are potent antioxidant activity. The analysis of qualitative and quantitative phytochemicals such as alkaloids, flavonoids, phenolic compounds, tannins, terpenoids and steroids revealed that the antioxidant activity of the YD and RD is due to these phytochemicals.

Key Words: Phoenix dactylifera, phytochemicals, antioxidant, flavonoids, phenolic compounds, alkaloids

\section{INTRODUCTION}

Phoneix dactyliferea commonly known as the date palm is an important plant in the scorched region of southwest Asia and North Africa. ${ }^{1}$ Dates are a good source of energy, vitamins and a group of elements like Phosphorus, Iron, Potassium and a significant amount of calcium. ${ }^{2}$ Besides its nutritional value date palm is also rich in phenolic compounds possessing antioxidant activity. The protection against oxidative stress in several diseases is mainly due to the presence of various antioxidants and vitamins present in the fruit. Antioxidants that can quench reactive free radicals can prevent the oxidation of other molecules and may therefore have health-promoting effects in the prevention of degenerative diseases. ${ }^{3}$ The interest in antioxidant has been increasing because of their high capacity in scavenging free radicals related to various diseases. ${ }^{4}$ Free radical oxidative stress has been implicated in the pathogenesis of a wide variety of clinical disorders such as cancer, diabetes, multiple sclerosis and arthritis. ${ }^{5}$ The human disease is believed to be due to the imbalance between oxidative, tissue damage and hence prevent diseases progression by antioxidant defence supplements. ${ }^{6}$ The in-vitro study reported that the aqueous extract of palm date fruit has antioxidative and anti-mutagenic properties. ${ }^{7}$ Flavonoids are known to possess anti-inflammatory, antioxidant, anti-allergic, hepatoprotective, anti-thrombotic, neuroprotective and anti-carcinogenic activities. ${ }^{8}$ However, studies deal with the fruit of date palm, not on the unripe or raw dates which were found to possess $\beta$ - carotene the antioxidant vitamin. Here in this study, we determined the phytochemical content and their antioxidant property of two different varieties of unripe date palm.

Corresponding Author:

M Gayathri, PhD scholar, Department of Food Science and Nutrition, Periyar University, Salem, Tamil Nadu-636403, India. E-mail: gaya3vimala@gmail.com

ISSN: 2231-2196 (Print)

Received: 27.08 .2020
ISSN: 0975-5241 (Online)

Revised: 21.10 .2020
Accepted: 15.12 .2020 


\section{MATERIALS AND METHODS}

\section{Sample collection}

Two different varieties of PhoneixdactylifereanamelyBarhi (Yellow colour date, YD) and Khenaizi (Red colour Date, RD) were procured from Shariah date palm located in Dharmapuri district of Tamilnadu in India in June and July 2018. The selected dates were such that, they are uniform in size, free from physical damage and injuries by insects and fungal infection. The sample was washed, cut (uniform thickness) and dried using a cabinet drier at $65^{\circ} \mathrm{C}$ then it was ground into a fine powder and used for analysis.

\section{Preparation of extract}

Briefly, the samples were processed according to the procedure. ${ }^{9}$ The finely powdered samples of both varieties were extracted using a soxhlet extractor approximately $50 \mathrm{gm}$ of the sample was suspended in $100 \mathrm{ml}$ of 5 solvents aqueous, methanol, benzene, petroleum ether and chloroform at room temperature for 3 hours and the extract was collected. The extract was evaporated to dryness and stored at $4^{\circ} \mathrm{C}$ until use.

\section{Qualitative phytochemical screening}

The prepared date palm extract was screened for the presence of phytochemicals using the method. ${ }^{10}$

\section{Quantitative phytochemical analysis}

The Quantitative Phytochemical analysis was performed on testing different chemical group which are present in unripe date palm powder using the standard analytical procedure. ${ }^{11}$

\section{Determination of antioxidant activities}

The antioxidant activities of unripe date palm powder were measured using 4 different methods namely 1 . DPPH(2, 2-diphenyl-1-picryl-hydrazyl-hydrate) free radical scavenging assay, 2. Ferrous ion chelating of activity, 3.Ferric reducing antioxidant power assay and 4.Superoxide dismutase activity method.

\section{DPPH free radical scavenging activity}

The antioxidant activities were measured in terms of hydrogen donating or radical scavenging ability using the stable radical DPPH. ${ }^{7}$ The analysis was carried out in a 96 well microtiter plate. The analysis was done using $200 \mu \mathrm{l}$ of DPPH solution to the $10 \mu \mathrm{l}$ of both test solution and the standard solution and kept separately in the wells of the microtiter plate. The final concentration of the test and standard solutions used were $250,200,150,100$, and $50 \mu \mathrm{g} / \mathrm{ml}$. The plates were incubated at $37^{\circ} \mathrm{C}$ for $30 \mathrm{~min}$ and the absorbance of each solution was measured at $490 \mathrm{~nm}$, using a 96 well microplate reader. The percentage inhibition of DPPH radical scavenging activity was calculated as follows.
$\%$ Inhibition $=[(\mathbf{A b}$ (blank) $-\mathbf{A s}($ sample $) / \mathbf{A b}($ blank $)] *$ 100

Where $\mathbf{A b}$ is the absorbents of blank As is the absorbents of sample.

\section{Measurement of ferrous ion chelating activity}

Iron-chelating abilities of the methanol extract of YD and RD and standards were estimated by the method. ${ }^{12}$ Four dilutions of dimethyl sulphano oxalate (DMSO) $(20 \mathrm{mg} / \mathrm{mL}, 10$ $\mathrm{mg} / \mathrm{mL}, 5 \mathrm{mg} / \mathrm{mL}$ and $2.5 \mathrm{mg} / \mathrm{mL}$ ) were prepared from the dried extracts. Briefly, $0.05 \mathrm{~mL}$ of each dilution was added to a $2.7 \mathrm{~mL}$ TRIS buffer $(\mathrm{pH}=7.4)$. Thereafter, $0.05 \mathrm{~mL}$ of 2 $\mathrm{mM} \mathrm{FeCl}{ }_{2}$ were added and vortexed for $15 \mathrm{sec}$. At $30 \mathrm{sec}$, the reaction was initiated by the addition of $5 \mathrm{mMferrozine}(0.2$ $\mathrm{mL}$ ), the mixture was shaken vigorously at Vortex (VelpScientifica, UE) for $10 \mathrm{sec}$. After 1 min beyond the addition of ferric chloride solution $\left(\mathrm{FeCl}_{2}\right)$, the absorbance of the solution was measured spectrophotometrically at $562 \mathrm{~nm}$. The ability of the sample extracts was calculated using the formula: chelating activity $(\%)=100 \times[(\mathrm{ACAS}) / \mathrm{AC}]$, where $\mathrm{AC}$ is the absorbance of the control, and AS is the absorbance of the sample.

\section{Ferric reducing antioxidant power assay}

Different concentrations of the methanol extract of RD and YD and its various fractions $(10-50 \mu \mathrm{g} / \mathrm{mL})$ was added to $2.5 \mathrm{~mL}$ of $0.2 \mathrm{M}$ sodium phosphate buffer $(\mathrm{pH} 6.6)$ and 2.5 $\mathrm{mL}$ of $1 \%$ potassium ferricyanide $\left[\mathrm{K}_{3} \mathrm{Fe}(\mathrm{CN})_{6}\right]$ solution. The reaction mixture was vortexed well and then incubated at $50^{\circ} \mathrm{C}$ for 20 min using a vortex shaker. At the end of the incubation, $2.5 \mathrm{~mL}$ of $10 \%$ trichloroacetic acid was added to the mixture and centrifuged at 3,000 rates per minute for $10 \mathrm{~min}$. The supernatant $(2.5 \mathrm{~mL})$ was mixed with $2.5 \mathrm{~mL}$ of deionised water and $0.5 \mathrm{~mL}$ of $0.1 \%$ ferric chloride. The coloured solution was read at $700 \mathrm{~nm}$ against the blank concerning standard using Ultra violetSpectrophotometer. Here, ascorbic acid was used as a reference standard, the reducing power of the samples was compared with the reference standard.

\section{Superoxide dismutase activity}

The Superoxide radical scavenging activity was measured by the method of Fontana et. al. Based on this method, the activity is measured by the reduction of riboflavin/light/NBT (Nitro blue tetrazolium). About $1 \mathrm{ml}$ of reaction mixture contained Phosphate buffer, NADH, NBT and various Concentrations of sample solution. Mainly the method is based on the generation of superoxide radical by auto-oxidation of riboflavin in presence of light. The Nitro Blue Tetrazoliumwas reduced by Superoxide radical to a blue coloured formazan that can be measured at $560 \mathrm{~nm}$. 


\section{RESULTS AND DISCUSSION}

YD and RD varieties of unripe date palm powder extracts were analyzed for their content of the phytochemical and antioxidant activity. Different Phytochemical have been found to possess a wide range of activities, which may help in protection against chronic diseases. ${ }^{13}$ Preliminary phytochemical of both varieties have been shown in Table 1 .

From the obtained results compared to all other extracts, the methanol extract showed the presence of more phytochemicals such as alkaloid, flavonoid, phenolic compounds, carbohydrates, saponin, steroid and tannin. RD contain a high concentration of phytochemicals than that of YD.

Shah Alam Khan et al., (2016) shows the date variety such as fourth has the order of solvent according to the extraction of phenolic compounds was observed to be acetone $>$ methanol $>$ ethanol $>$ water while for khasab it was in the order of ethanol $>$ methanal $>$ acetone $>$ water. ${ }^{14}$ Alkaloid exhibit marked physiological effects when administrated to animals and hence their wide use in medicine for the development of drugs. ${ }^{15}$

The protective role of flavonoids was especially flavanols\&flavonols from cardiovascular and cancer diseases have pointed. ${ }^{16}$ Tannin is reported to exhibit antiviral, antibacterial, antitumoral activities. It was also reported as some tannin was used as a diuretic. ${ }^{17}$ Saponin which is responsible for numerous pharmacological properties..$^{18}$ Phenolics can manifest in type II diabetes by inhibiting the activities of $\alpha$ glycosidase and $\alpha$ amylase to increase blood glucose level. ${ }^{19}$ Steroids or Sterols of plants are called phytosterols and possess Myriad health benefits. ${ }^{20}$ The ratio and concentration of these constituents depend on the type of the fruit, stage of fruit picking, location and soil conditions. These also contribute to the organoleptic properties of the fruit. ${ }^{21}$

Table 1: Screening of phytochemical on YD and RD variety using different solvents

\begin{tabular}{|c|c|c|c|c|c|c|c|c|c|c|}
\hline \multirow{2}{*}{$\begin{array}{l}\text { Solvents } \\
\text { components }\end{array}$} & \multicolumn{2}{|c|}{ Aqueous } & \multicolumn{2}{|c|}{ Methanol } & \multicolumn{2}{|c|}{ Benzene } & \multicolumn{2}{|c|}{ Petroleum ether } & \multicolumn{2}{|c|}{ Chloroform } \\
\hline & RD & YD & $\mathbf{R D}$ & YD & RD & YD & RD & YD & RD & YD \\
\hline Alkaloid & ++ & ++ & +++ & ++ & + & + & ND & ND & ND & ND \\
\hline Flavonoid & +++ & ++ & +++ & +++ & + & + & + & + & + & ND \\
\hline Phenolic compounds & ++ & ++ & +++ & +++ & + & + & + & + & + & + \\
\hline Saponin & ++ & ++ & +++ & +++ & ND & ND & ND & ND & ++ & ++ \\
\hline Tannin & ++ & ++ & +++ & ++ & ++ & ++ & + & + & + & + \\
\hline Steroid & + & + & +++ & ++ & + & + & + & + & ND & ND \\
\hline carbohydrate & +++ & ++ & +++ & ++ & + & + & + & + & + & ND \\
\hline
\end{tabular}

RD red dates (Khenaizi) YD yellow dates (Barhi)

$+++=$ High, $++=$ Moderate, $+=$ Low, ND = Not Detectable

\section{Table 2: Phytochemical content of unripe date palm}

\begin{tabular}{llcc} 
S. no & Phytochemicals & RD $(\mathrm{g} / \mathbf{1 0 0 g})$ & YD $(\mathrm{g} / \mathbf{1 0 0 g})$ \\
1. & Alkaloids & $2.36 \pm 0.13$ & $1.89 \pm 0.97$ \\
2. & Flavonoids & $4.17 \pm 0.19$ & $3.75 \pm 0.03$ \\
3. & Anthraquoine & $0.19 \pm 1.16$ & $0.14 \pm 0.12$ \\
4. & Saponin & $0.02 \pm 0.08$ & $0.01 \pm 0.05$ \\
5. & Terpenoids & $0.08 \pm 1.07$ & $0.05 \pm 1.14$ \\
6. & Tannin & $0.86 \pm 0.15$ & $0.49 \pm 0.01$ \\
\hline
\end{tabular}

$\mathrm{RD}$ red dates, YD yellow dates

Table 2 shows that the phytochemical content of the RD seemed to be in a higher concentration than that of YD. The alkaloid content of RD was about $2.36 \pm 0.13$ and YD was $1.89 \pm 0.97$. The alkaloid produced analgesic anti-spasmodic and bactericidal effect. ${ }^{22}$ Flavonoids present in plants possess diverse health benefits which include antioxidant and radical scavenging activities, deduction of certain chronic disease, prevention of some cardiovascular disorders and certain types of a cancerous process. ${ }^{23}$ From the result the flavonoid content of RD was high as about $4.17 \pm 0.19$ and low in YD as $3.75 \pm 0.03$. The flavonoid and alkaloid content of the date palm fruit was about 34.29 and $5.20 \%$ respectively. ${ }^{24}$ Likewise the anthraquinone content of RD and YD was about $0.19 \pm 1.16$ and $0.14 \pm 0.12$ respectively. Triterpe- 
noids and Saponin showed analgesic properties and central nervous system activities..$^{25}$ The concentration of the value of saponin in both RD and YD were about $0.02 \pm 0.08$ and $0.01 \pm 0.05$ respectively, which is within the WHO permissible limit of $48.50 \mathrm{mg} / 100 \mathrm{~g}$ as recommended $2003 .{ }^{26}$ The terpenoid content of RD was about $0.08 \pm 1.07$ and YD was about $0.05 \pm 1.14$. Similarly RD has a high content of Tannin at about $0.86 \pm 0.15$ than that of YD at about $0.49 \pm 0.01$. The tannin content of date palm fruit is about $7.51 \% .{ }^{27}$ From the phytochemicals tannin is understood to react with protein to supply the standard tanning effect that's important for the treatment of inflamed or ulcerated tissues. ${ }^{28}$

\section{In vitro antioxidant activities of YD and RD date palm}

Among the four antioxidant activity assay, the methanol extract of red dates shows more \% inhibition than that of yellow dates. Several methods and modification have been used for the measurement of antioxidant activity. A single method is not enough to assay the whole antioxidant activity therefore application and combination of several tests recommended providing a better description. The scavenging activity of both samples was expressed as \% inhibition and was compared with standard antioxidant as ascorbic acid.

As a result, shows that the concentration of both samples increased the \% inhibition as the concentration of sample increases. This means that the data indicating the hydrogen donating ability of the sample antioxidants such as phenolic compounds. This is similarly based on another study which relates the hydrogen donating ability using the DPPH method to the presence of phenolic and polyphenolic compounds. ${ }^{29}$ In the presence of hydrogen donors, DPPH is oxidized and stable free radical is formed from the scavengers. The methanol extract of RD showed higher \% inhibition as $94.05 \pm$ 2.73 for $100 \mu \mathrm{g} / 1 \mathrm{ml}$ concentration, for the same concentration YD shows a lower effect as $85.13 \pm 2.74$.

Date fruit has the second antioxidant activity among 28 fruits by using the FRAP test. ${ }^{30}$ FRAP assay of methanol extract of both samples were done. The value is compared to that of the standard antioxidant as vitamin C. RD had greater antioxidant activity as $77.91 \pm 2.96$ for $100 \mu \mathrm{g} / \mathrm{ml}$ concentration, but the YD had only $68.03 \pm 2.66$ for the same concentration.

Iron is essential for life because it is required for oxygen transport, respiration and the activity of many enzymes. ${ }^{31}$ Iron can generate free radicals from peroxides by Fenton reactions. So the production of these radicals can lead to lipid peroxidation, protein modification and DNA damage. ${ }^{32}$ Minimization of $\mathrm{Fe}^{2+}$ concentrations in the Fenton reaction affords protection against oxidative damage. ${ }^{27}$ Chelation of Fe 2+ ions activity of methanol extract of both samples were shown higher \% inhibition compared to YD (79.64 \pm 4.0$)$, $\mathrm{RD}$ had higher value such as $88.02 \pm 2.50$ for $100 \mu \mathrm{g} / \mathrm{ml}$ concentration.

Superoxide radical scavenging activity of methanol extract of RD had $82.50 \pm 2.58 \%$ inhibition, but the YD had only $72.30 \pm 2.10 \%$ inhibition for $100 \mu \mathrm{g} / \mathrm{ml}$ concentration. The antioxidant activity of RD and YD extract was estimated at different concentration in methanol extract and the result was graphically shown in figures 1-4.

Table 3: In vitro antioxidant activities of YD and RD date palm

\begin{tabular}{|c|c|c|c|c|c|}
\hline Sample & $\begin{array}{l}\text { concentration } \\
(\mu \mathrm{g} / \mathbf{1 0 0 \mathrm { ml } )}\end{array}$ & $\begin{array}{c}\text { DPPH } \\
\% \text { inhibition }\end{array}$ & $\begin{array}{c}\text { FRAP } \\
\% \text { inhibition }\end{array}$ & $\begin{array}{c}\mathrm{Fe}^{2+} \text { Chel } \\
\% \text { inhibition }\end{array}$ & $\begin{array}{c}\text { SOD } \\
\% \text { inhibition }\end{array}$ \\
\hline \multirow{5}{*}{$\begin{array}{l}\text { Methanol extract of } \\
\text { red dates }\end{array}$} & 100 & $94.05 \pm 2.73$ & $77 \cdot 91 \pm 2.96$ & $88.02 \pm 2.50$ & $82.50 \pm 2.58$ \\
\hline & 80 & $86.37 \pm 4.79$ & $60.83 \pm 3.77$ & $80.74 \pm 3.24$ & $69.28 \pm 4.55$ \\
\hline & 60 & $80.28 \pm 3.40$ & $49 \cdot 32 \pm 3.11$ & $69.80 \pm 2.74$ & $52.07 \pm 4.29$ \\
\hline & 40 & $69.43 \pm 4.03$ & $28.62 \pm 2.84$ & $50.18 \pm 3.57$ & $40.11 \pm 1.96$ \\
\hline & 20 & $58.94 \pm 3.19$ & $19.53 \pm 3.19$ & $34.71 \pm 1.35$ & $21.38 \pm 2.50$ \\
\hline \multirow{5}{*}{$\begin{array}{l}\text { Methanol extract of } \\
\text { yellow dates }\end{array}$} & 100 & $85.13 \pm 2.74$ & $68.03 \pm 2.66$ & $79.64 \pm 4.0$ & $72.30 \pm 2.10$ \\
\hline & 80 & $70.57 \pm 1.53$ & $59.20 \pm 1.11$ & $62.70 \pm 1.75$ & $60.94 \pm 2.30$ \\
\hline & 60 & $56.10 \pm 1.85$ & $45.17 \pm 3.83$ & $51.13 \pm 2.60$ & $48.06 \pm 2.93$ \\
\hline & 40 & $42.93 \pm 3.3$ & $30.45 \pm 3.86$ & $39.60 \pm 3.89$ & $21.83 \pm 3.39$ \\
\hline & 20 & $30.78 \pm 2.4$ & $22.08 \pm 2.67$ & $24.68 \pm 3.15$ & $14.07 \pm 3.19$ \\
\hline \multirow{5}{*}{$\begin{array}{l}\text { Standard } \\
\text { Ascorbic acid }\end{array}$} & 50 & $97 \cdot 31 \pm 1.06$ & $89.16 \pm 4.05$ & $91.36 \pm 3.81$ & $87 \cdot 32 \pm 2.69$ \\
\hline & 40 & $90.58 \pm 3.06$ & $80.06 \pm 4.24$ & $83.09 \pm 3.69$ & $70.08 \pm 2.94$ \\
\hline & 30 & $81.20 \pm 2.94$ & $68.39 \pm 2.31$ & $70.25 \pm 2.85$ & $58.30 \pm 3.40$ \\
\hline & 20 & $73 \cdot 38 \pm 4.17$ & $50.05 \pm 2.68$ & $58.40 \pm 4.15$ & $39.88 \pm 4.09$ \\
\hline & 10 & $61.46 \pm 2.65$ & $39.28 \pm 2.75$ & $40.97 \pm 1.40$ & $28.03 \pm 3.90$ \\
\hline
\end{tabular}


The graph shows the methanol extract of both the RD and YD varieties against the standard ascorbic acid. Among all the antioxidant activity assay the methanol extract of RD shows more effect than that of YD.

\section{CONCLUSION}

The detailed information from this study confirms that both YD and RD unripe date palm demonstrated high phytochemical content and are potent antioxidant activity. The analysis of qualitative and quantitative phytochemicals such as alkaloids, flavonoids, phenolic compounds, tannins, terpenoids and steroids revealed that the antioxidant activity of the YD and RD is due to these phytochemicals. The antioxidant activity was tested using various methods like DPPH, FRAP, $\mathrm{Fe}^{2+}$ and SOD proved that YD and RD are potent antioxidant and could be used as a supplement for the prevention of oxidative stress.

\section{ACKNOWLEDGEMENT}

The author acknowledges the immense help received from the laboratory where the analysis had been done. The author is also thankful to the authors, editors, publishers of all those articles, journals and books from where the literature for this article has been reviewed and discussed.

Source of funding: This article has been prepared without funding and as an independent study under the guidance of Dr. S. Thilagavathi

Conflict of interest: The author expresses no conflict of interest

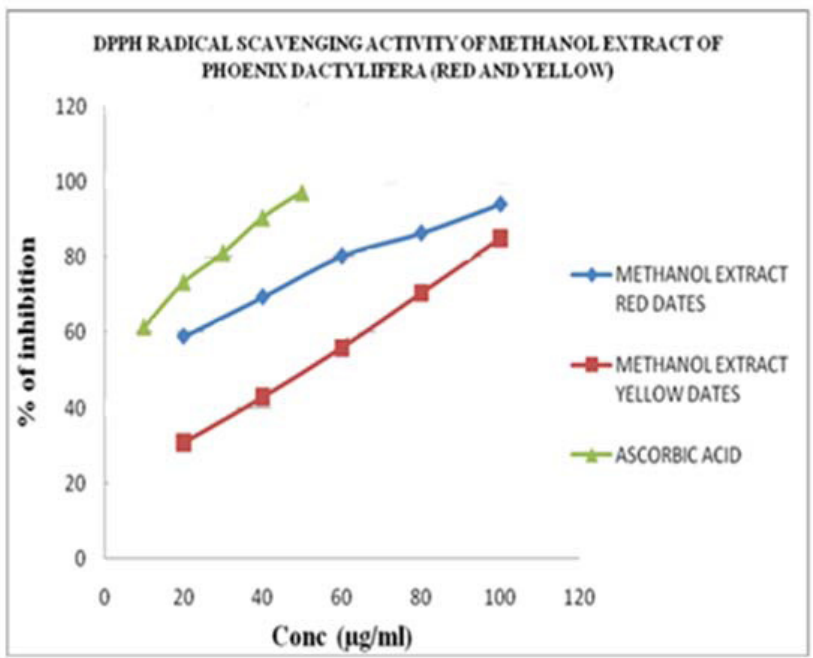

Figure 1: Dpph activity of methanol extract of phoenix dactylifera (red and yellow).

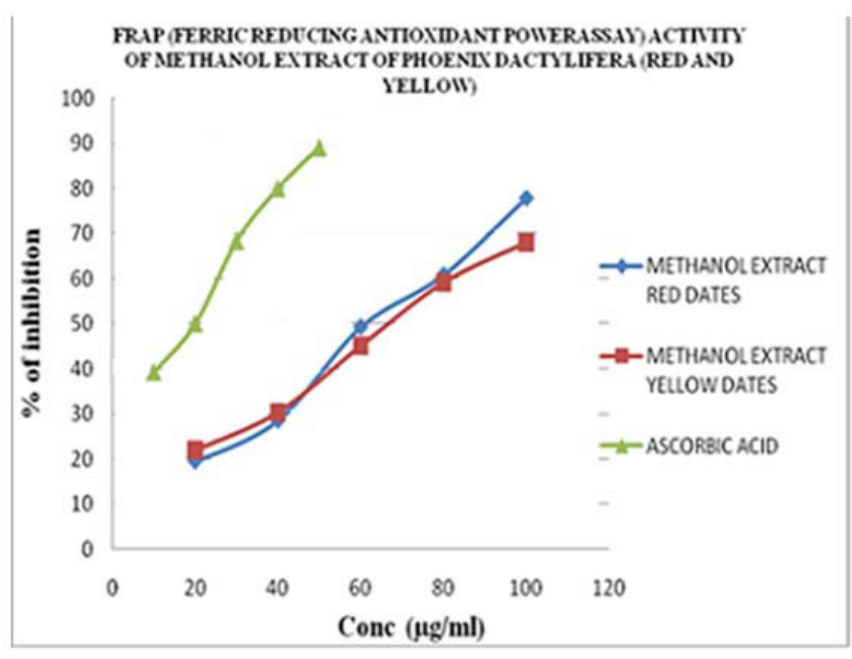

Figure 2: FRAP (ferric reducing antioxidant powerassay) activity of methanol extract of phoenix dactylifera (red and yellow).

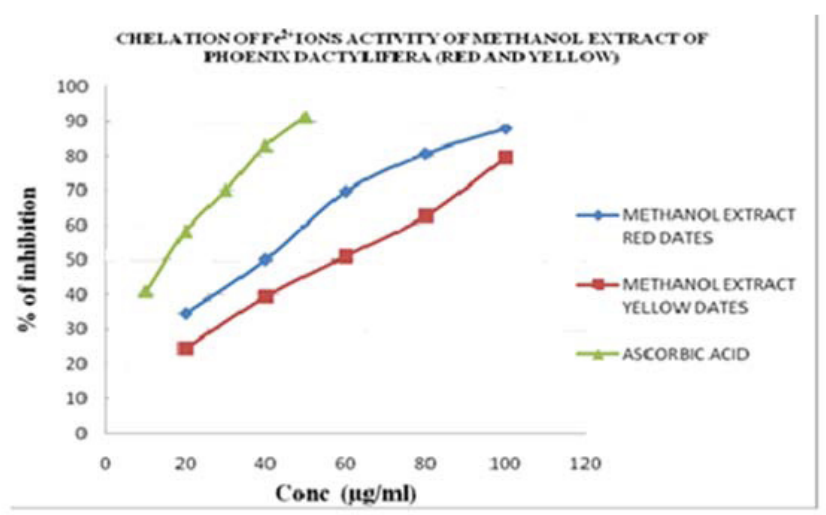

Figure 3: Chelation of fe2+ions activity of methanol extract of phoenix dactylifera (red and yellow).

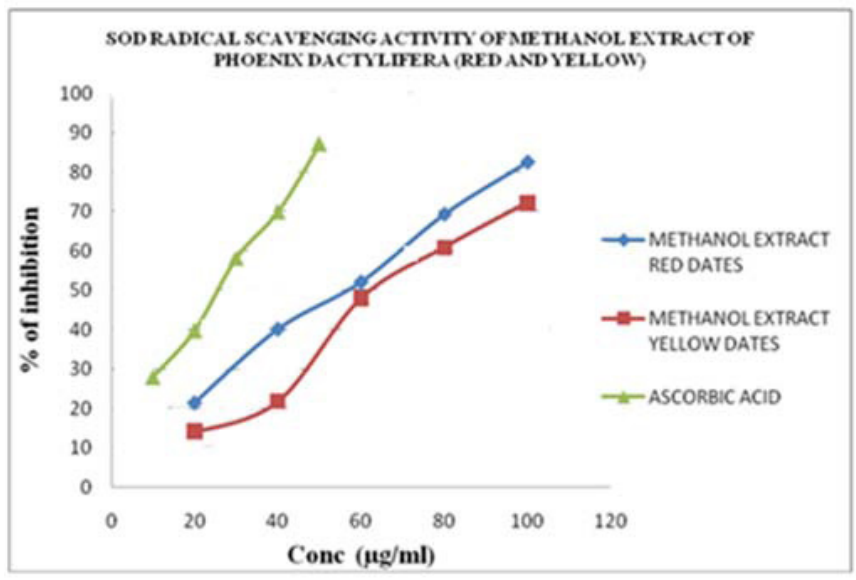

Figure 4: SOD radicals scavenging activity of methanol extract of phoenix dactylifera (red and yellow). 


\section{REFERENCES}

1. Al-Farsi MA, Lee CY. Nutritional and functional properties of dates: a review. Crit Rev Food Sci Nutr 2008;48(10):877-887.

2. Anwar-Shinwari M. Iron content of date fruits. J Colle Sci King Saud Uni 1987;18(1):5-13.

3. Shahidi F, editor. Natural antioxidants: chemistry, health effects, and applications. The American Oil Chemists Society; 1997.

4. Silva EM, Souza JN, Rogez H, Rees JF, Larondelle Y. Antioxidant activities and polyphenolic contents of fifteen selected plant species from the Amazonian region. Food Chem 2007;101(3):1012-1018.

5. Halliwell B, Gutteridge JM. [1] Role of free radicals and catalytic metal ions in human disease: an overview. In Methods in enzymology 1990 Jan 1 (Vol. 186, pp. 1-85). Academic Press.

6. Bhattacharya A, Chatterjee A, Ghosal S, Bhattacharya SK. Antioxidant activity of active tannoid principles of Emblica officinalis (amla). Indian J Exp Biol 1999;37:676-680.

7. Vayalil PK. Antioxidant and antimutagenic properties of aqueous extract of date fruit (Phoenix dactylifera L. Arecaceae). J Agricult Food Chem 2002;50(3):610-617.

8. Sala A, Recio MC, Schinella GR, Máñez S, Giner RM, CerdáNicolás M, Ríos JL. Assessment of the anti-inflammatory activity and free radical scavenger activity of tiliroside. E J Pharmacol 2003;461(1):53-61.

9. Sofowora A. Medicinal plants and traditional medicine in Africa" spectrum books limited, Ibadan, Nigeria (1993) pp. 220-224.

10. Krishnaiah D, Devi T, Bono A, Sarbatly R. Studies on phytochemical constituents of six Malaysian medicinal plants. J Med Plants Res 2009;3(2):67-72.

11. Trease GE, Evans WC. Pharmacognosy. 15th ed. London:SaundersPublishers.AnalyticalChemistry1994;34:1314-1326.

12. Harris GM, Livingstone SE. Bidentate chelates. In: Dwyer, FP.Millor, D.P. (Eds). In: chelating agents and metal chelates. Vol. 1. Academic press, Newyork, (1964) P.95.

13. Augusti KT, Cherian S. Insulin sparing action of leucopelargonidin derivative isolated from Ficus bengalesis Linn. Indian J Exp Biol 2008;33:608-611.

14. Khan SA, Rashid AA, Saif MA, Salim T. In-vitro inhibitory effects on $\alpha$-glucosidase and $\alpha$ - amylase level and antioxidant potential of seeds of phoenix dactylifera L. Asian Pac J Trop Biomed 2016;6(4):322-329.

15. Okwu DE. Phytochemicals, vitamins and mineral contents of two Nigerian medicinal plants. Int $\mathrm{J}$ Mol Med Adv Sci 2005; 1(4):375-381.

16. Hassimotto NM, Genovese MI, Lajolo FM. Antioxidant activity of dietary fruits, vegetables, and commercial frozen fruit pulps. J Agricult Food Chem 2005;53(8):2928-2935.

17. Heslem E. Plant polyphenol vegetal tannin relisted-chemistry and pharmacology of natural products. Cambridge University Press, Cambridge, Massachusetts. 1989.
18. Estrada A, Katselis GS, Laarveld B, Barl B. Isolation and evaluation of immunological adjuvant activities of saponins from Polygala senega L. Compar Immunol Microbiol Infect Dis 2000;23(1):27-43.

19. McCue PP, Shetty K. Inhibitory effects of rosmarinic acid extracts on porcine pancreatic amylase in vitro. Asia Pac J Clin Nutr 2004;13(1).

20. Liolios CC, Sotiroudis GT, Chinou I. Fatty acids, sterols, phenols and antioxidant activity of Phoenix theophrasti fruits growing in Crete, Greece. Plant Foods Human Nutr 2009;64(1):52-61.

21. Mansouri A, Embarek G, Kokkalou E, Kefalas P. Phenolic profile and antioxidant activity of the Algerian ripe date palm fruit (Phoenix dactylifera). Food Chem 2005;89(3):411-420.

22. Stray F. The Natural Guide to medicinal Herbs and Plants. Tiger Books International. Londan, (1998) Pp: 12-16.

23. Tapas AR, Sakarkar DM, Kakde RB. Flavonoids as nutraceuticals: a review. Trop J Pharm Res 2008;7(3):1089-1099.

24. Shaba EY, Ndamitso MM, Mathew JT, Etsunyakpa MB, Tsado AN, Muhammad SS. Nutritional and anti-nutritional composition of date palm (Phoenix dactylifera L.) fruits sold in major markets of Minna Niger State, Nigeria. Afr J Pure Appl Chem 2015;9(8):167-174.

25. Sayyah M, Hadidi N, Kamalinejad M. Analgesic and anti-inflammatory activity of Lactuca sativa seed extract in rats. J Ethnopharmacol 2004;92(2-3):325-329.

26. WHO. Feeding and nutrition of infants and young children guidelines for the WHO European region with emphasis on the former Soviet Union. WHO Regional publications, European series (2003) 87:1-296.

27. Rival SG, Boeriu CG, Wichers HJ. Caseins and casein hydrolysates. 2. Antioxidative properties and relevance to lipoxygenase inhibition. J Agricult Food Chem 2001;49(1):295-302.

28. Parekh J, Chanda S. In vitro antibacterial activity of the crude methanol extract of Woodfordia fruticosa Kurz. Flower (Lythraceae). Braz J Microbiol 2007;38(2):204-7.

29. Conforti F, Loizzo MR, Statti GA, Menichini F. Comparative Radical Scavenging and Antidiabetic Activities of Methanolic Extract and Fractions from Achillea ligustica A LL. Biol Pharm Bull 2005;28(9):1791-1794.

30. Guo C, Yang J, Wei J, Li Y, Xu J, Jiang Y. Antioxidant activities of peel, pulp and seed fractions of common fruits as determined by FRAP assay. Nutr Res 2003;23(12):1719-1726.

31. Duh PD, Yen GC, Yen WJ, Chang LW. Antioxidant effects of water extracts from barley (Hordeum vulgare L.) prepared under different roasting temperatures. J Agricult Food Chem 2001;49(3):1455-1463.

32. Leong LP, Shui G. An investigation of antioxidant capacity of fruits in Singapore markets. Food Chem 2002;76(1):69-75. 